\title{
An Element-Driven Boundary Integral Treatment for Nonlinearity: A Coupled Nonlinear Two-Dimensional Burger's Equation Test Case
}

\author{
Okey Oseloka Onyejekwe \\ Computational Science Program Addis Ababa University Arat Kilo Campus, Addis Ababa, Ethiopia
}

Email address:

okuzaks@yahoo.com

To cite this article:

Okey Oseloka Onyejekwe. An Element-Driven Boundary Integral Treatment for Nonlinearity: A Coupled Nonlinear Two-Dimensional Burger's Equation Test Case. International Journal of Fluid Mechanics \& Thermal Sciences. Vol. 3, No. 1, 2017, pp. 1-15.

doi: 10.11648/j.ijfmts.20170301.11

Received: December 11, 2016; Accepted: December 26, 2016; Published: January 24, 2017

\begin{abstract}
To further improve on the competitiveness of the boundary element method (BEM), a hybrid version of it is used for a numerical solution of two dimensional nonlinear coupled viscous Burger's equation. Adopting this approach to a discretized 2D spatial domain, the resulting integral equations arising from the singular integral theory are applied locally to each of the elements. The resulting nonlinear discrete equations are finally solved by the Picard iteration algorithm. The simulation results obtained, not only concur with analytical solutions, but also display high accuracy and are in agreement with those available in literature.
\end{abstract}

Keywords: Two Dimensional, Coupled Nonlinear Burger'S Equation, Hybrid Boundary Element Method, Integral Equation, Singular Integral Theory, Discretization

\section{Introduction}

The two dimensional coupled nonlinear Burger's equation forms an important class of a system of nonlinear parabolic and hyperbolic partial differential equations (PDEs) that models unsteady flow equations. It bears a close resemblance to the Navier-Stokes equations by incorporating the same convective and diffusive terms but differs by the absence of the pressure term. It is often used to study various aspects of physical phenomena involving among others turbulence, flow through shockwaves [1], sedimentation of particles in fluid suspensions or colloids under the effect of gravity [2], wave processes in thermo-elastic medium [3], dispersion in porous media, and vorticity transport.

The analytic solution of the coupled nonlinear Burger's equation involving various transformation techniques are given by Fletcher [4], Abazari and Borhanifar [5] and Ablowitz and Clarkson [6]. Other powerful methods of arriving at exact solutions include the homotopy perturbation method, Hirota's bilinear method (Hirota [7]), and the delta method (Bender et al. [8]). Kaya [9], Zhu et. Al. [10] solved the system of coupled Burger's equation by the Adomian decomposition method. Comparison between exact nonlinear equation solutions and those obtained numerically were carried out by Fletcher [11], Abdou and Soliman [12]. A combination of the homotopy perturbation and Pade' approximation were applied by Kelleci and Yildrim [13] to study both the homogeneous and inhomogeneous coupled Burger's equation.

The finite element method (FEM) in combination with the spline-interpolation techniques have been used to solve the coupled nonlinear Burger's equation (Kutluay, and Ucar [14]). Higher order accurate schemes have also been used (Esipov [3]). This is accompanied by those involving variational iteration method (Soliman 2009 [15], Abdou and Soliman [12]), Odibat and Momani [16]). Bahadir [17] applied a finite -difference fully implicit technique to the discretization of coupled nonlinear Burger's equation and resolved the nonlinearity with the Newton's method. Other finite difference applications can be found in Srivastava et al. [18], Srivastava et al. [19]. These followed earlier work by Wubs and Goede [20], and Goyon [21].

BEM literature reveals a paucity of information regarding the application of boundary element methods to the solution 
of coupled nonlinear partial differential equations especially for 2D coupled nonlinear Burger's equation Onyejekwe [22]. It is well known that considerable numerical difficulties arise in extending BEM application to inhomogeneous, non-linear, transient, coupled nonlinear problems Grigoriev [23], Sirajul-islam et al. [24], Toutip [25]. The major drawback in these cases is the need to discretize the problem domain into an aggregation of cells or elements needed to deal with domain integrations. It will not be possible to go into details here. A comprehensive literature on this topic can be found in Grigoriev's paper [23]. However it is noted that the current research trajectory of BEM still reveals an unresolved issue namely the drive to restrict or situate all domain integrals on the boundaries of the problem domain even if the physics of the problem dictates otherwise. The compelling need to make BEM a purely boundary-driven numerical technique motivates this trend. Unfortunately this is often accompanied by some numerical challenges some of which have been mentioned above and in some previous papers (Percher et al. [26], Lorinczi [27], Lorinczi et al. [28], Archer et al. [29], Archer [30], Onyejekwe [31, 32], Onyejekwe and Onyejekwe [33] Archer and Horne [34]).

Numerical experience shows that direct application of BEM theory performs poorly in the absence of a strong link between the problem domain and the boundary as is found in the Laplace equation. Hence there is always a need to modify BEM application for those problems that unambivalently incorporate the problem domain into problem formulation such as is found with body-force terms, nonlinearity, transience, heterogeneity, source and sink terms etc. Current efforts to prevail over this challenge have resulted in a variety of hybrid BEM techniques Grigoriev [23], Taigbenu [35], Onyejekwe [36], Onyejekwe [37], Taigbenu and Onyejekwe [38], Hibersek and Skerget [39], Onyejekwe [40], Grigoriev and Dargush [41], Perata and Popov [42], Portapilla and Power [43], Sladeck et al. [44], Toutip [25].

Hybrid BEM formulations, as promising simulation techniques, can either be regarded as extensions of the direct BEM approach or in most cases as specialized discrete forms of the traditional formulation that weigh more on the effective handling of the integral equations in a domainlocalized sense. It ought to be mentioned as well that one of the reasons that prompted this option is the unavailability of auxiliary equations and/or fundamental solutions for many challenging and realistic problems. Even when they exist, they do so in forms that are not easily computable. More often than not, this leads to intricate formulations and systems of equations with fully populated matrix. Hence aiming at hybrid BEM formulations that mimic other domain-based numerical methods in terms of localized discretizations, and at the same time incorporate some of their unique advantages should motivate hybrid BEM research. This approach brings a lot of attractive features such as formulation simplicity, slender sparse coefficient matrices and an efficient handling of domain discretization. Hybrid BEM techniques have not only displayed competitive potential in modelling complex engineering problems (Abashar [45], Pecher et al. [26], Onyejekwe [46-48], Lorinczi et al. [27, 28] Lorinczi et al. (2010), Nyirenda [49], Bagherinezhad and Pishvaie [50], Archer and Horne [51, 52] but also have displayed a remarkable ability to accurately represent coupled nonlinear mathematical equations (Ramsuroop [53]).

\section{Numerical Formulation}

Consider the two-dimensional non-linear Burger's equation:

$$
\begin{aligned}
& \frac{\partial u}{\partial t}+u \frac{\partial u}{\partial x}+v \frac{\partial u}{\partial y}=\kappa \nabla^{2} u \\
& \frac{\partial v}{\partial t}+u \frac{\partial v}{\partial x}+v \frac{\partial v}{\partial y}=\kappa \nabla^{2} v
\end{aligned}
$$

where $\nabla^{2}=\mathbf{i} \partial / \partial x+\mathbf{j} \partial / \partial y$ is the 2-D gradient operator with spatial variables in $\mathrm{x}$ and $\mathrm{y}, \mathrm{t}$ is the time dimension, $\kappa=1 / \operatorname{Re} . \operatorname{Re}$ is the Reynolds number and physically represents the ratio of inertia to viscous forces, $u(x, y, t), v(x, y, t)$ are velocity components in $\mathrm{x}$ and $\mathrm{y}$ directions to be determined. It should be mentioned that in convection dominated flows, there is a steepening effect of the nonlinear advection term, and this effect creates noticeable numerical challenges. Equations (1a) and (1b) admit initial and boundary conditions. For a domain $\Omega=\{(x, y): a \leq x, y \leq b\}$ with a boundary $\Gamma$, the system is subject to the following initial conditions

$$
\begin{array}{ll}
u(x, y, 0)=\beta_{1}(x, y), \quad(x, y) \in \Omega \quad \text { or } \quad \forall(x, y) \in \Omega \\
v(x, y, 0)=\beta_{2}(x, y), \quad(x, y) \in \Omega \quad \text { or } \quad \forall(x, y) \in \Omega
\end{array}
$$

And boundary conditions:

$$
\begin{gathered}
u(x, y, t)=g_{1}(x, y), \quad(x, y) \in \Gamma \quad \text { or } \quad \forall(x, y) \in \Gamma \quad t \succ 0 \\
v(x, y, t)=g_{2}(x, y), \quad(x, y) \in \Gamma \quad \text { or } \quad \forall(x, y) \Gamma \quad t \succ 0
\end{gathered}
$$

where $\beta_{1}, \beta_{2} g_{1}$ and $g_{2}$ are known functions.

\section{Hybrid BEM Procedure}

Details of this procedure have previously been dealt with elsewhere (Onyejekwe [54-56], Lorinczi [27, 28], Archer [30], Ramsuroop [53], Onyejekwe [54-56]); so only the most relevant will be mentioned. By Applying the Green's theorem, the integral analogs of equations (1a) and (1b) are given as:

$$
-\lambda u\left(r_{i}, t\right)+\int_{\Gamma}\left(u \frac{\partial G}{\partial n}+G \frac{\partial u}{\partial n}\right) d s+\iint_{\Omega} \frac{G}{\kappa}\left[\left(u \frac{\partial u}{\partial x}+v \frac{\partial u}{\partial y}+\frac{\partial u}{\partial t}\right)\right] d A=0
$$




$$
-\lambda v\left(r_{i}, t\right)+\int_{\Gamma}\left(v \frac{\partial G}{\partial n}+G \frac{\partial v}{\partial n}\right) d s+\iint_{\Omega} \frac{G}{\kappa}\left[\left(u \frac{\partial v}{\partial x}+v \frac{\partial v}{\partial y}+\frac{\partial v}{\partial t}\right)\right] d A=0
$$

or

$$
-\lambda u\left(r_{i}, t\right)+\int_{\Gamma}(u \nabla G \cdot \mathbf{n}+G \nabla u \cdot \mathbf{n}) d s+\iint_{\Omega} G\left[\frac{1}{\kappa}\left(\frac{\partial u}{\partial t}\right)-\left(\left\{\frac{u}{\kappa}\right\}\left\{\frac{q_{x}}{\kappa}\right\}+\left\{\frac{v}{\kappa}\right\}\left\{\frac{q_{y}}{\kappa}\right\}\right)\right] d A=0
$$

where $q_{x}=-\kappa \nabla u \cdot \mathbf{i}, q_{y}=-\kappa \nabla u \cdot \mathbf{j}$

and

$$
-\lambda v\left(r_{i}, t\right)+\int_{\Gamma}(v \nabla G \cdot \mathbf{n}+G \nabla v \cdot \mathbf{n}) d s+\iint_{\Omega} G\left[\frac{1}{\kappa}\left(\frac{\partial v}{\partial t}\right)-\left(\left\{\frac{u}{\kappa}\right\}\left\{\frac{s_{x}}{\kappa}\right\}+\left\{\frac{v}{\kappa}\right\}\left\{\frac{s_{y}}{\kappa}\right\}\right)\right] d A=0
$$

where $s_{x}=-\kappa \nabla v \cdot \mathbf{i}, s_{y}=-\kappa \nabla v \cdot \mathbf{j}$

where $G=\ln \left(z_{i}\right)$ is the fundamental solution of $\nabla^{2} G=\delta\left(z_{i}\right)$ in an infinite domain, $z_{i}=r-r_{i}$ is the Euclidean distance between the field point and the source node at $\mathrm{i}, \lambda$ is the shape function of the nodal angle at $r_{i}$. Although equations (4) and (5) were arrived at by exploiting the attractive features of BEM discretization, their implementation vis-à-vis the problem domain marks the point of departure between the boundary-only implementation of BEM and its hybridized form that does not consider domain integration as a disadvantage. To this end, suitable polygonal elements on which the discretized equations are numerically solved are employed to discretize the problem domain. A domain-driven-elemental approach exemplifies the limiting case of the domain decomposition technique whereby the subdomain is reduced to its barest minimum or finite elements (Taigbenu [35], Onyejekwe [36]). The key factors which are paramount at this stage of the solution process are identical to those of the finite element method (FEM) namely (a) linearization of the governing equations (b) interpolation of the functional quantities and continuity across element boundaries (c) choice of elements. For this study, we have elected to represent the distribution of scalar quantities by linear interpolation functions, that is $\phi \approx N_{j} \phi_{j}$ where $N_{j}$ are the linear interpolation functions. Introducing this interpolation relationship into equations (5a) and (5b) yields the following discrete element equations which are applicable to each element.

$$
R_{i j} u_{j}+L_{i j}\left(\frac{q}{\kappa}\right)_{j}+\chi_{i m j}\left[\left(\frac{u}{k}\right)_{m}\left(\frac{q_{x}}{k}\right)_{j}\right]+\Upsilon_{i m j}\left[\left(\frac{v}{k}\right)_{m}\left(\frac{q_{x}}{k}\right)_{j}\right]+\Psi_{i j}\left[\left(\frac{1}{\kappa} \frac{d u}{d t}\right)_{j}\right]=0
$$

where $q=-\kappa \nabla u \cdot \mathbf{n}$

and

$$
R_{i j} v_{j}+L_{i j}\left(\frac{s}{\kappa}\right)_{j}+\chi_{i m j}\left[\left(\frac{u}{k}\right)_{m}\left(\frac{s_{x}}{k}\right)_{j}\right]+\Upsilon_{i m j}\left[\left(\frac{v}{k}\right)_{m}\left(\frac{s_{y}}{k}\right)_{j}\right]+\Psi_{i j}\left[\left(\frac{1}{\kappa} \frac{d v}{d t}\right)_{j}\right]=0
$$

where $s=-\kappa \nabla v \cdot \mathbf{n}$

The coefficients are given by:

$$
\begin{gathered}
R_{i j}=\int_{\Gamma}\left(N_{j} \nabla G \cdot \mathbf{n}\right) d s-\delta_{i j} \lambda, \quad L_{i j}=\int_{\Gamma}\left(N_{j} d s\right), \quad \chi_{i m j}=\iint_{\Omega} G\left(\frac{\partial N_{m}}{\partial x} N_{j}\right) d A \\
\Upsilon_{i m j}=\iint_{\Omega} G\left(\frac{\partial N_{m}}{\partial y} N_{j}\right) d s, \quad \Psi_{i j}=\iint_{\Omega} G\left(N_{j}\right) d A
\end{gathered}
$$

All integrations can be done analytically for each of the rectangular elements. Without any loss in generality equations (6a) and (6b) can be given generically as: 


$$
\mathbf{A}^{n} \Phi^{n+1}+\mathbf{B}^{n} \mathbf{q}^{n+1}+\mathbf{C}^{n} \frac{d \Phi^{n+1}}{d t}=0
$$

The temporal derivative in equation (7) is approximated by a finite difference scheme with a weighting factor $\omega$ to give

$$
\omega\left(\mathbf{A}^{n} \Phi^{(n+2, m+1)}\right)+(1-\omega)(\mathbf{A} \Phi)^{(m)}+\omega\left(\mathbf{A}^{n} \mathbf{q}^{(n+2, m+1)}\right)+(1-\omega)(\mathbf{B q})^{(m)}+\mathbf{C}^{(n)} \frac{\Phi^{(n+1, m+1)}-\Phi^{(n+1, m+1)}}{\Delta t}=0
$$

where $\mathrm{n}$ is the iteration number, $m+1, m$ represent the current $\left(t_{1}=t_{0}+\Delta t\right)$ and previous $\left(t_{0}\right)$ times. With the introduction of known initial and boundary conditions, equation (8) can further be simplified into its coupled components to read:

$$
\begin{gathered}
\mathbf{Z}^{(n)} \mathbf{u}^{(n+1, m+1)}+\mathbf{Q}^{(n)} \mathbf{q}^{(n+1, m+1)}=(\text { RHS })_{1} \\
\mathbf{J}^{(n)} \mathbf{v}^{(n+1, m+1)}+\mathbf{W}^{(n)} \mathbf{s}^{(n+1, m+1)}=(\text { RHS })_{2}
\end{gathered}
$$

The Picard algorithm is adopted for iterating the two nonlinear coupled equations and is started by:

a Storing the known scalar values obtained from prescribed initial and boundary conditions in the right hand side vectors of equations (9) and (10)

b Solving matrix equation (9) with the known values to obtain updated values of the scalar field $\left(\mathbf{u}^{(n+1, m+1)}, \mathbf{q}^{(n+1, m+1)}\right)$

c These latest iterates from (b) are then used to obtain the scalar field from equation (10) i.e. $\left(\mathbf{v}^{(n+1, m+1)}, \mathbf{s}^{(n+1, m+1)}\right)$

d The mean deviations from the latest iterates from the consecutive values of the dependent variables in (b) and (c) are compared and the iteration is stopped if the mean deviations are less than or equal to an a priori specified error tolerance $\in$ ?. If this is not the case the procedure from steps (b) to (c) are repeated with refined iterates until convergence if finally achieved.

e When convergence is finally achieved, a time increment is implemented to obtain a new set of converged scalar field for each time level.

\section{Numerical Examples and Discussion}

Some test problems have been chosen to validate the formulation described herein. The presence of analytical results will help to quantify the relative performance of this scheme when compared with other solution methods available in literature. For each of the tested problems, the initial and boundary conditions are determined by their analytical solutions.

The accuracy and consistence of the scheme is measure in terms of errors defined by:

$$
\text { relative error }=\frac{1}{(\Delta x \Delta y)} \sqrt{\frac{\sum_{i=0}^{n} \sum_{j=0}^{n}\left|u_{i, j}^{\text {exact }}-u_{i, j}^{\text {computed }}\right|^{2}}{\sum_{i=0}^{n} \sum_{j=0}^{n}\left|u_{i, j}^{\text {exact }}\right|^{2}}}
$$

$$
\text { average absolute error }=\frac{1}{\Delta x \Delta y}\left|u_{i, j}^{\text {exact }}-u_{i, j}^{\text {computed }}\right|
$$

where $u_{\text {exact }}, u_{\text {computed }}$ represent exact and computed solutions. Equations (13a) and (13b) will also apply to the $v$ dependent variable.

\subsection{Problem 1}

The exact solutions of equations (1) and (2) can be generated as shown in Fletcher (1983a):

$$
\left.\begin{array}{l}
u(x, y, t)=\frac{3}{4}-\frac{1}{4[1+\exp ((-4 x+4 y-t) \operatorname{Re} / 32)]} \\
v(x, y, t)=\frac{3}{4}+\frac{1}{4[1+\exp ((-4 x+4 y-t) \operatorname{Re} / 32)]}
\end{array}\right\} \quad(x, y) \in \Omega
$$

The computational domain is a square $\Omega=\{(x, y): 0 \leq x \leq 1,0 \leq y \leq 1\}$, a uniform grid is applied with a mesh dimension of $\Delta x=\Delta y=0.05$ with the following problem parameters $\operatorname{Re}=100, \Delta t=0.001$. Comparison of numerical and exact solutions shows that the proposed formulation achieves very close results for different values of Reynolds number. Figs. $1 \mathrm{a}$ and $1 \mathrm{~b}$ are very close to those obtained analytically (Tamsir and Srivasta [57]). Tables $1 \mathrm{a}, 1 \mathrm{~b}, 1 \mathrm{c}$ and $1 \mathrm{~d}$ display the absolute errors resulting from a comparison of numerical and analytical results for velocity profiles at different values of Reynolds number. A revealing information is the magnitude of absolute errors generated in representing areas of steep slope in the $\mathrm{u}$ and $\mathrm{v}$ velocity profiles. Figs. 1c and $1 \mathrm{~d}$ display their relative magnitudes relative to those obtained in other areas of the profiles.

Table 1a. Numerical results for $u$ velocity in comparison with exact solutions at $t=0.5$ for $R e=100, \Delta t=.0001$, (example 1).

\begin{tabular}{llll}
\hline $\mathbf{( x , y )}$ & Numerical & Exact & Abs. Error \\
\hline$(0.100000,0.100000)$ & 0.534028 & 0.543322 & 0.009294 \\
$(0.500000,0.100000)$ & 0.500270 & 0.500353 & 0.000083 \\
$(0.900000,0.100000)$ & 0.500002 & 0.500002 & 0.000000 \\
$(0.300000,0.300000)$ & 0.516242 & 0.543322 & 0.027080 \\
$(0.700000,0.300000)$ & 0.500028 & 0.500353 & 0.000324 \\
$(0.100000,0.500000)$ & 0.735927 & 0.742214 & 0.006287 \\
$(0.500000,0.500000)$ & 0.534824 & 0.543322 & 0.008498 \\
$(0.900000,0.500000)$ & 0.500269 & 0.500353 & 0.000084 \\
$(0.300000,0.700000)$ & 0.734717 & 0.742214 & 0.007498 \\
$(0.700000,0.700000)$ & 0.542311 & 0.543322 & 0.001011 \\
$(0.100000,0.900000)$ & 0.749901 & 0.749946 & 0.000045 \\
$(0.500000,0.900000)$ & 0.741808 & 0.742214 & 0.000406 \\
$(0.900000,0.900000)$ & 0.539545 & 0.543322 & 0.003778 \\
\hline
\end{tabular}


Table 1b. Numerical results for $v$ velocity in comparison with exact solutions at $t=0.5$ for $\operatorname{Re}=100, \Delta t=.0001$, (example 1).

\begin{tabular}{llll}
\hline$(\mathbf{x}, \mathbf{y})$ & Numerical & Exact & Abs. Error \\
$(0.100000,0.100000)$ & 0.965972 & 0.956678 & 0.009294 \\
$(0.500000,0.100000)$ & 0.999730 & 0.999647 & 0.000083 \\
$(0.900000,0.100000)$ & 0.999998 & 0.999998 & 0.000000 \\
$(0.300000,0.300000)$ & 0.983758 & 0.956678 & 0.027080 \\
$(0.700000,0.300000)$ & 0.999972 & 0.999647 & 0.000324 \\
$(0.100000,0.500000)$ & 0.764073 & 0.757786 & 0.006287 \\
$(0.500000,0.500000)$ & 0.965176 & 0.956678 & 0.008498 \\
$(0.900000,0.500000)$ & 0.999731 & 0.999647 & 0.000084 \\
$(0.300000,0.700000)$ & 0.765283 & 0.757786 & 0.007498 \\
$(0.700000,0.700000)$ & 0.957689 & 0.956678 & 0.001011 \\
$(0.100000,0.900000)$ & 0.750099 & 0.750054 & 0.000045 \\
$(0.500000,0.900000)$ & 0.758192 & 0.757786 & 0.000406 \\
$(0.900000,0.900000)$ & 0.960455 & 0.956678 & 0.003778 \\
\hline
\end{tabular}

Table 1c. Numerical results for $u$ velocity in comparison with exact solutions at $t=0.5$ for $R e=50, \Delta t=.0001$, (example 1).

\begin{tabular}{llll}
\hline $\mathbf{( x , y )}$ & Numerical & Exact & Abs. (?) Error \\
\hline$(0.100000,0.100000)$ & 0.571735 & 0.578513 & 0.006778 \\
$(0.500000,0.100000)$ & 0.507501 & 0.509055 & 0.001554 \\
$(0.900000,0.100000)$ & 0.500633 & 0.500769 & 0.000136 \\
$(0.300000,0.300000)$ & 0.557219 & 0.578513 & 0.021294 \\
$(0.700000,0.300000)$ & 0.505997 & 0.509055 & 0.003058 \\
$(0.100000,0.500000)$ & 0.702971 & 0.711992 & 0.009021 \\
$(0.500000,0.500000)$ & 0.566951 & 0.578513 & 0.011562 \\
$(0.900000,0.500000)$ & 0.507953 & 0.509055 & 0.001102 \\
$(0.300000,0.700000)$ & 0.700424 & 0.711992 & 0.011568 \\
$(0.700000,0.700000)$ & 0.577499 & 0.578513 & 0.001014 \\
$(0.100000,0.900000)$ & 0.745264 & 0.746374 & 0.001110 \\
$(0.500000,0.900000)$ & 0.710125 & 0.711992 & 0.001867 \\
$(0.900000,0.900000)$ & 0.578351 & 0.578513 & 0.000162 \\
\hline
\end{tabular}

Table 1d. Numerical results for $v$ velocity in comparison with exact solutions at $t=0.5$ for $\operatorname{Re}=50, \Delta t=.0001$, (example 1 )

\begin{tabular}{llll}
\hline $\mathbf{( x ,} \mathbf{y})$ & Numerical & Exact & Abs. Error \\
\hline$(0.100000,0.100000)$ & 0.928265 & 0.921487 & 0.006778 \\
$(0.500000,0.100000)$ & 0.992499 & 0.990945 & 0.001554 \\
$(0.900000,0.100000)$ & 0.999367 & 0.999231 & 0.000136 \\
$(0.300000,0.300000)$ & 0.942781 & 0.921487 & 0.021294 \\
$(0.700000,0.300000)$ & 0.994003 & 0.990945 & 0.003058 \\
$(0.100000,0.500000)$ & 0.797029 & 0.788008 & 0.009021 \\
$(0.500000,0.500000)$ & 0.933049 & 0.921487 & 0.011562 \\
$(0.900000,0.500000)$ & 0.992047 & 0.990945 & 0.001102 \\
$(0.300000,0.700000)$ & 0.799576 & 0.788008 & 0.011568 \\
$(0.700000,0.700000)$ & 0.922501 & 0.921487 & 0.001014 \\
$(0.100000,0.900000)$ & 0.754736 & 0.753626 & 0.001110 \\
$(0.500000,0.900000)$ & 0.789875 & 0.788008 & 0.001867 \\
$(0.900000,0.900000)$ & 0.921649 & 0.921487 & 0.000162 \\
\hline
\end{tabular}




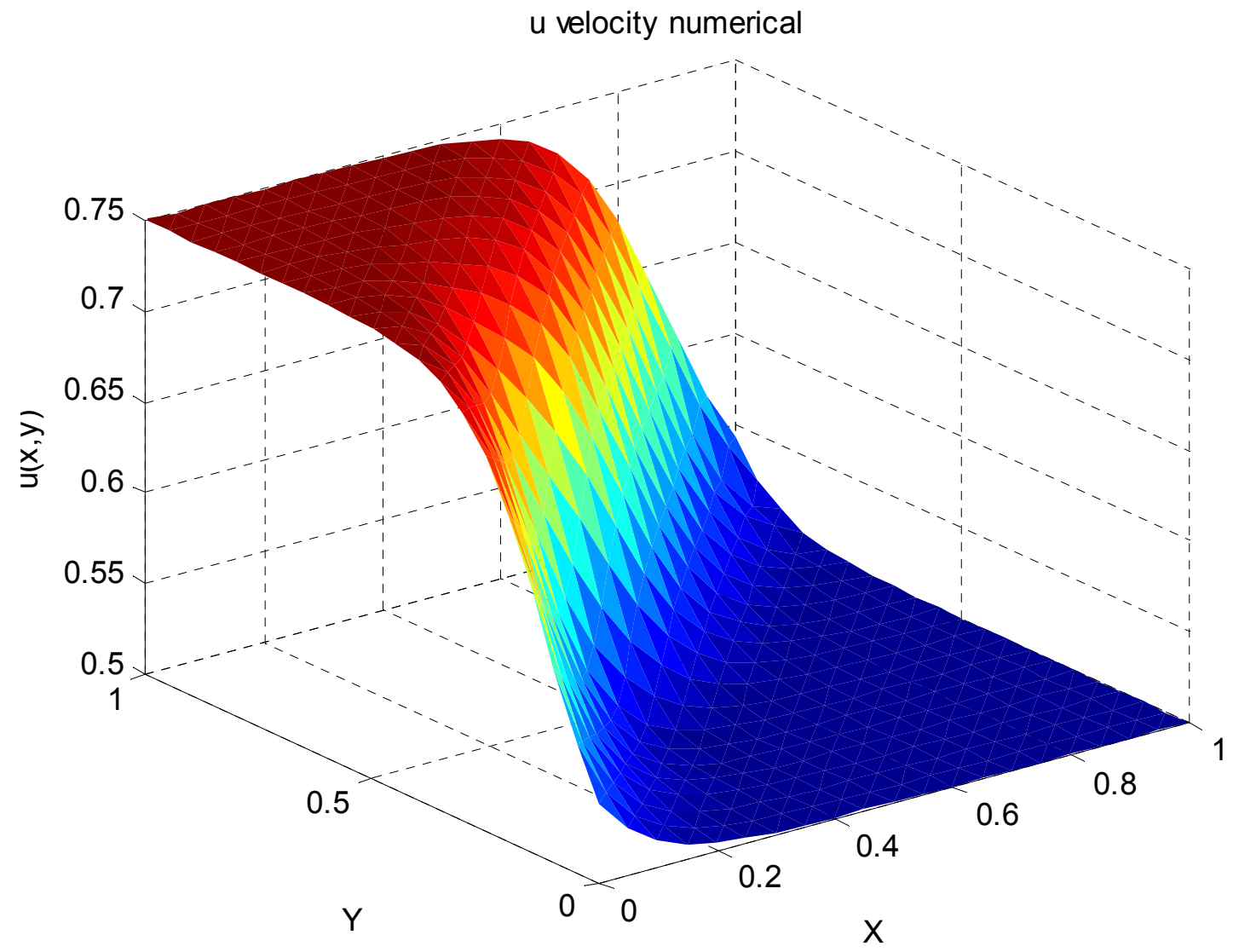

Fig. 1a. U velocity profile at $t=0.5$ for $R e=100, \Delta t=.0001$, (example 1).

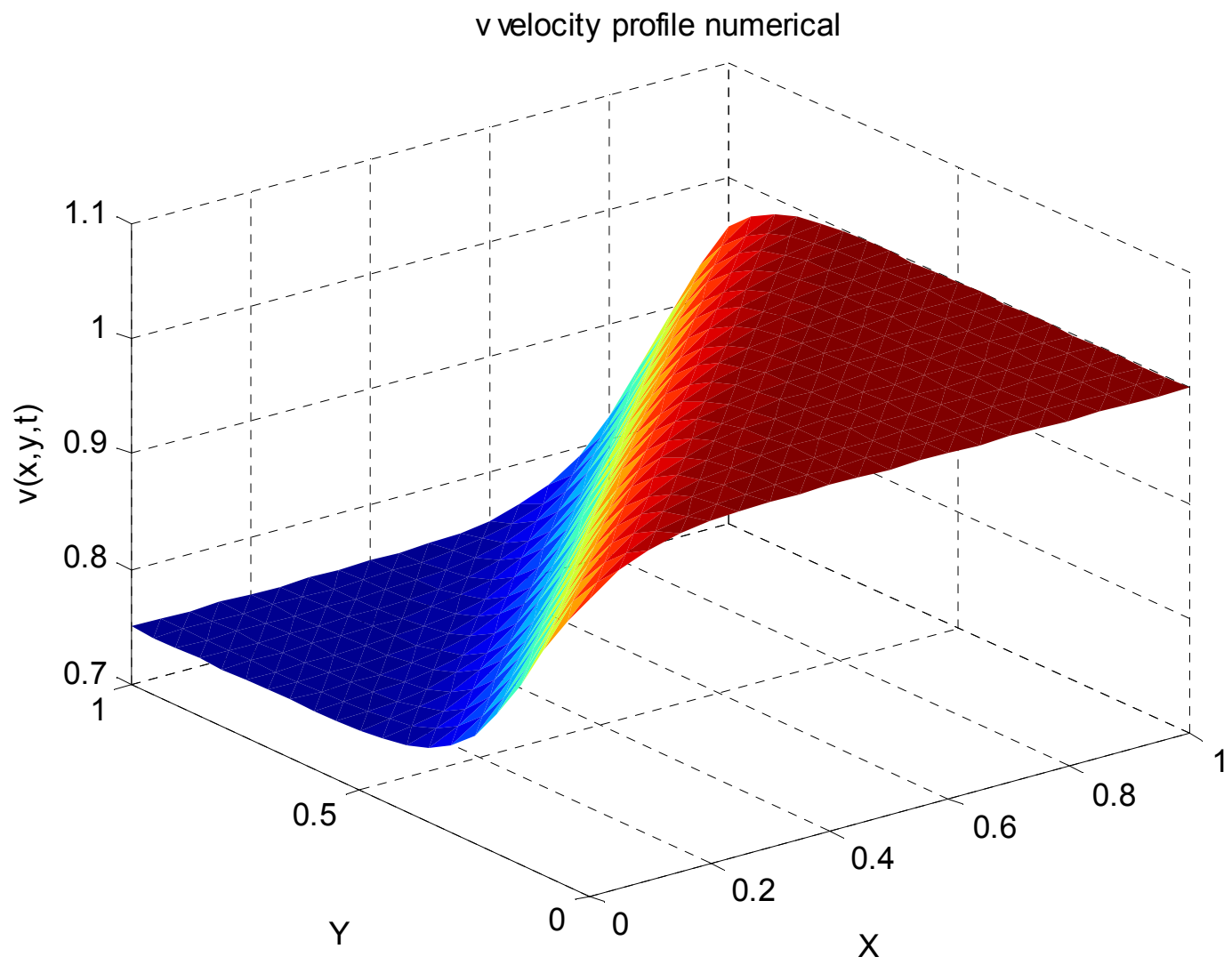

Fig. 1b. V velocity profile at $t=0.5$ for $R e=100, \Delta t=.0001$, (example 1$)$. 


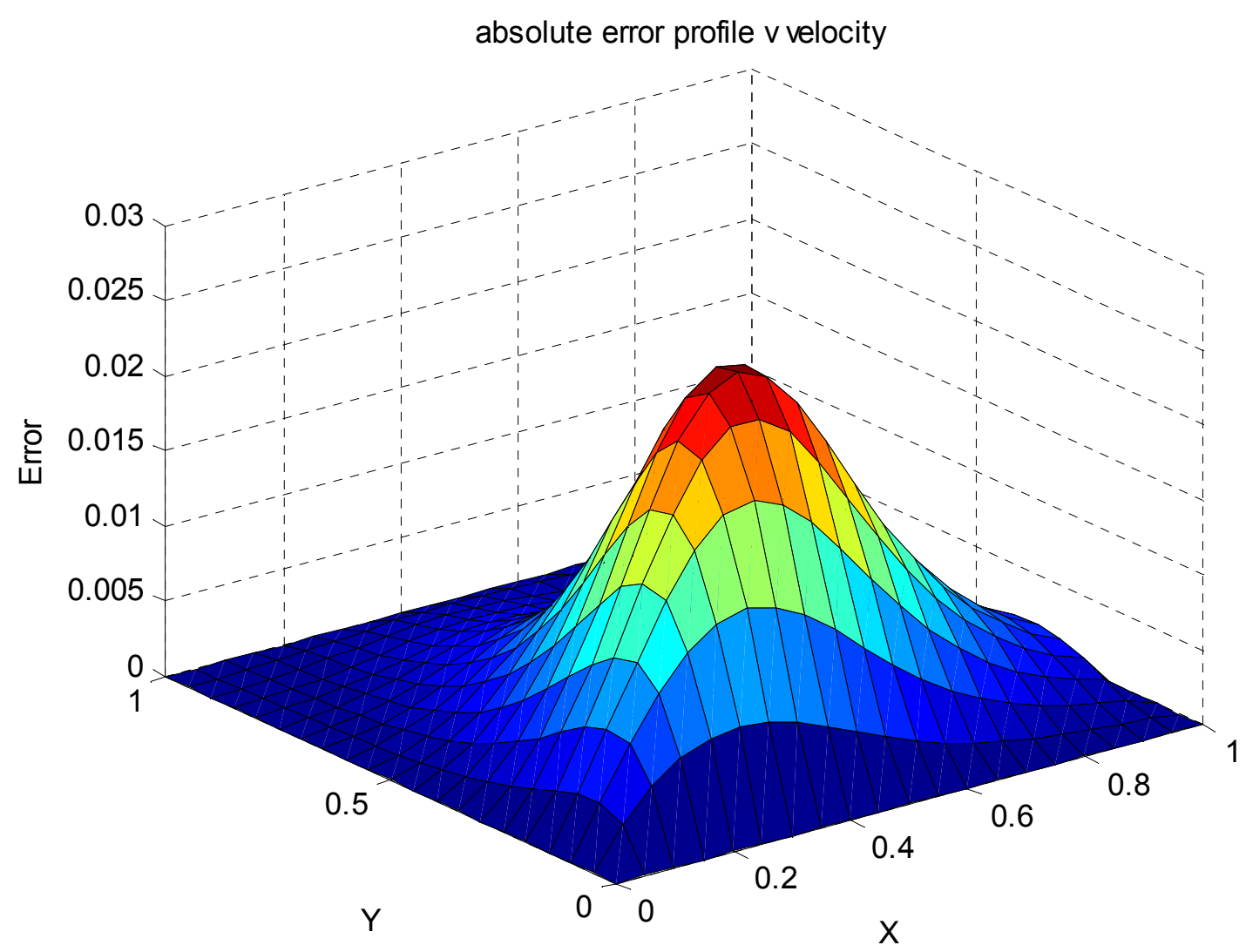

Fig. 1c. Absolute error profile $u$ velocity at $t=0.5$ for $R e=50, \Delta t=.0001$, (example 1)

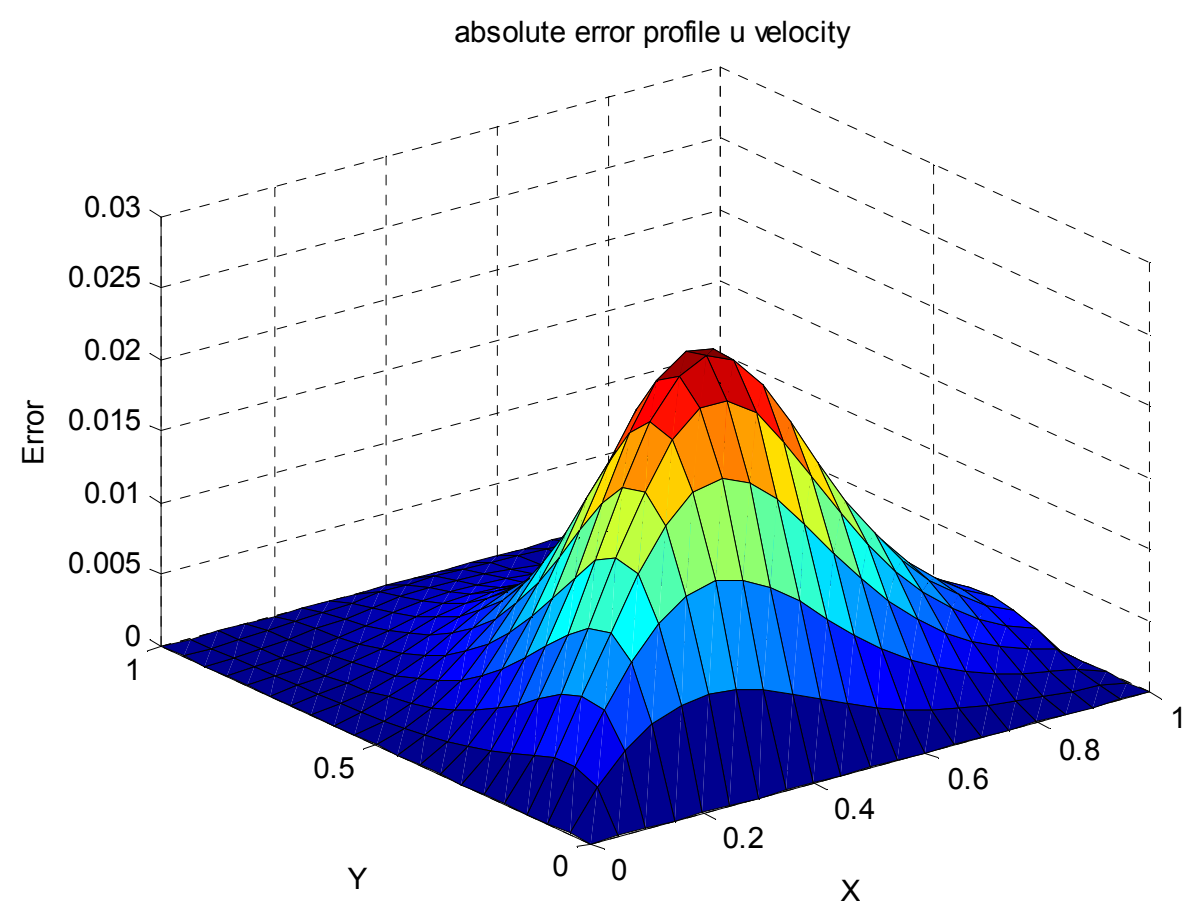

Fig. 1d. Absolute error profile for $v$ velocity at $t=0.5$ for $R e=50, \Delta t=.0001$, (example 1).

\subsection{Problem 2}

The computational domain is given as $\Omega=\{(x, y): 0 \leq x \leq 0.5,0 \leq y \leq 0.5\}$ and the initial and boundary conditions are:

$$
\left.\begin{array}{c}
u(x, y, 0)=\sin (\pi x)+\cos (\pi y) \\
v(x, y, 0)=x+y
\end{array}\right\} \quad 0 \leq x \leq 0.5,0 \leq y \leq 0.5(x, y)
$$

and 


$$
\begin{gathered}
\left.\begin{array}{c}
u(0, y, t)=\cos (\pi y), u(0.5, y, t)=1+\cos (\pi y) \\
v(0, y, t)=y, \quad v(0.5, y, t)=0.5+y
\end{array}\right\} \quad 0 \leq y \leq 0.5, t \geq 0 \\
\left.\begin{array}{c}
u(x, 0, t)=1+\sin (\pi x), u(x, 0.5, t)=\sin (\pi x) \\
v(x, 0, t)=x, \quad v(x, 0.5, t)=0.5+x
\end{array}\right\} \quad 0 \leq x \leq 0.5, t \geq 0
\end{gathered}
$$$$
0 \leq y \leq 0.5, t \geq 0 \quad(13 \mathrm{~b})
$$

We deploy $20 \times 20$ grids for the numerical computations for $\Delta t=0.0001$ and $\mathrm{Re}=50$ and $\mathrm{Re}=100$. There are no analytical solutions to compare our results with in this case.
However figs. $2 \mathrm{a}, 2 \mathrm{~b}, 2 \mathrm{c}$ and $2 \mathrm{~d}$ of $u$ and $v$ velocity profiles are very close to those of Shukla et al. [60]. In addition Tables $2 \mathrm{a}$ and $2 \mathrm{~b}$ show a comparison of numerical values

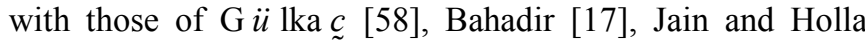
[59], Srivastava et $a l$. [18]. They all appear to give very close profiles for the $\mathrm{u}$ and $\mathrm{v}$ velocities.

Table 2a. Comparison of numerical results for u velocity profile at $t=0.625$, for $R e=50 \Delta t=.0001$ (example 2).

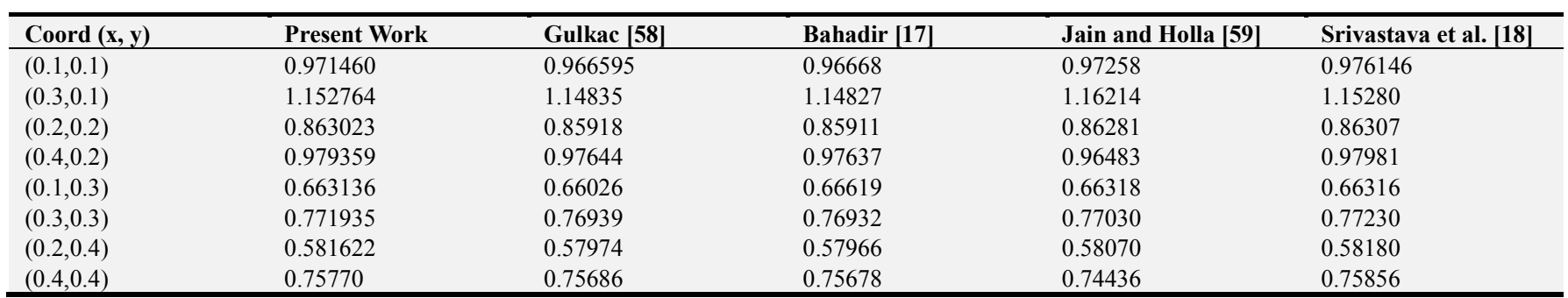

Table 2b. Comparison of numerical results for $v$ velocity profile at $t=0.625$, for $R e=50 \Delta t=.0001$ (example 2)

\begin{tabular}{lllll}
\hline Coord (x, y) & Present Work & Gulkac [58] & Bahadir [17] & Jain and Holla [59] \\
\hline$(0.1,0.1)$ & 0.098688 & 0.09832 & 0.09824 & 0.09773 \\
$(0.3,0.1)$ & 0.141566 & 0.14119 & 0.4112 & 0.14039 \\
$(0.2,0.2)$ & 0.167525 & 0.16689 & 0.16681 & 0.16660 \\
$(0.4,0.2)$ & 0.170948 & 0.17073 & 0.17065 & 0.17397 \\
$(0.1,0.3)$ & 0.263771 & 0.26269 & 0.26261 & 0.26940 \\
$(0.3,0.3)$ & 0.226400 & 0.22582 & 0.22576 & 0.14158 \\
$(0.2,0.4)$ & 0.328432 & 0.32754 & 0.32745 & 0.16754 \\
$(0.4,0.4)$ & 0.324710 & 0.32447 & 0.32441 & 0.17110 \\
\hline
\end{tabular}

$\mathrm{v}$ velocity at $\mathrm{t}=0.625, \mathrm{Re}=50$

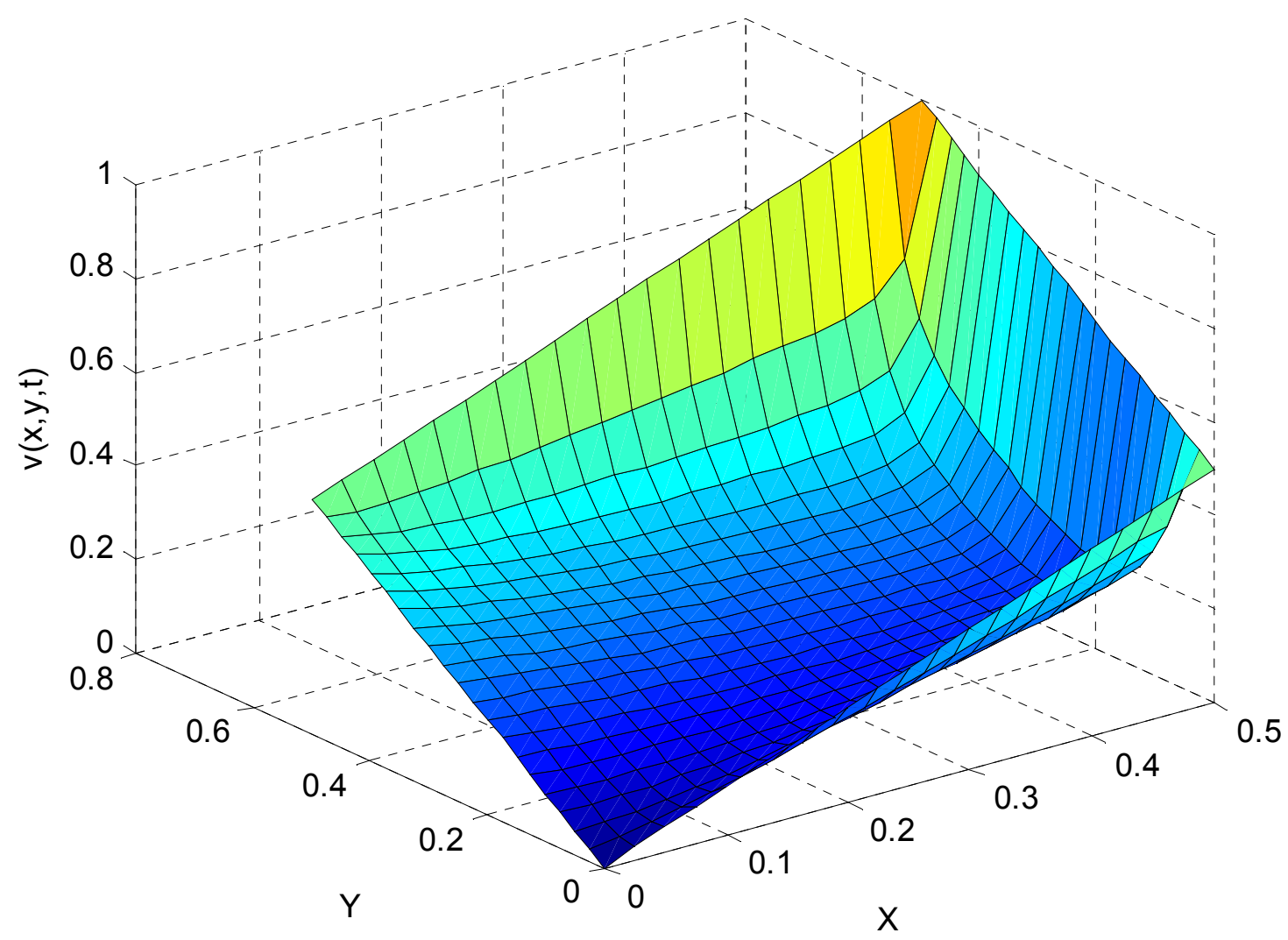

Fig. 2a. V velocity profile at $t=0.625$ for $R e=50, \Delta t=.0001$, (example 2). 


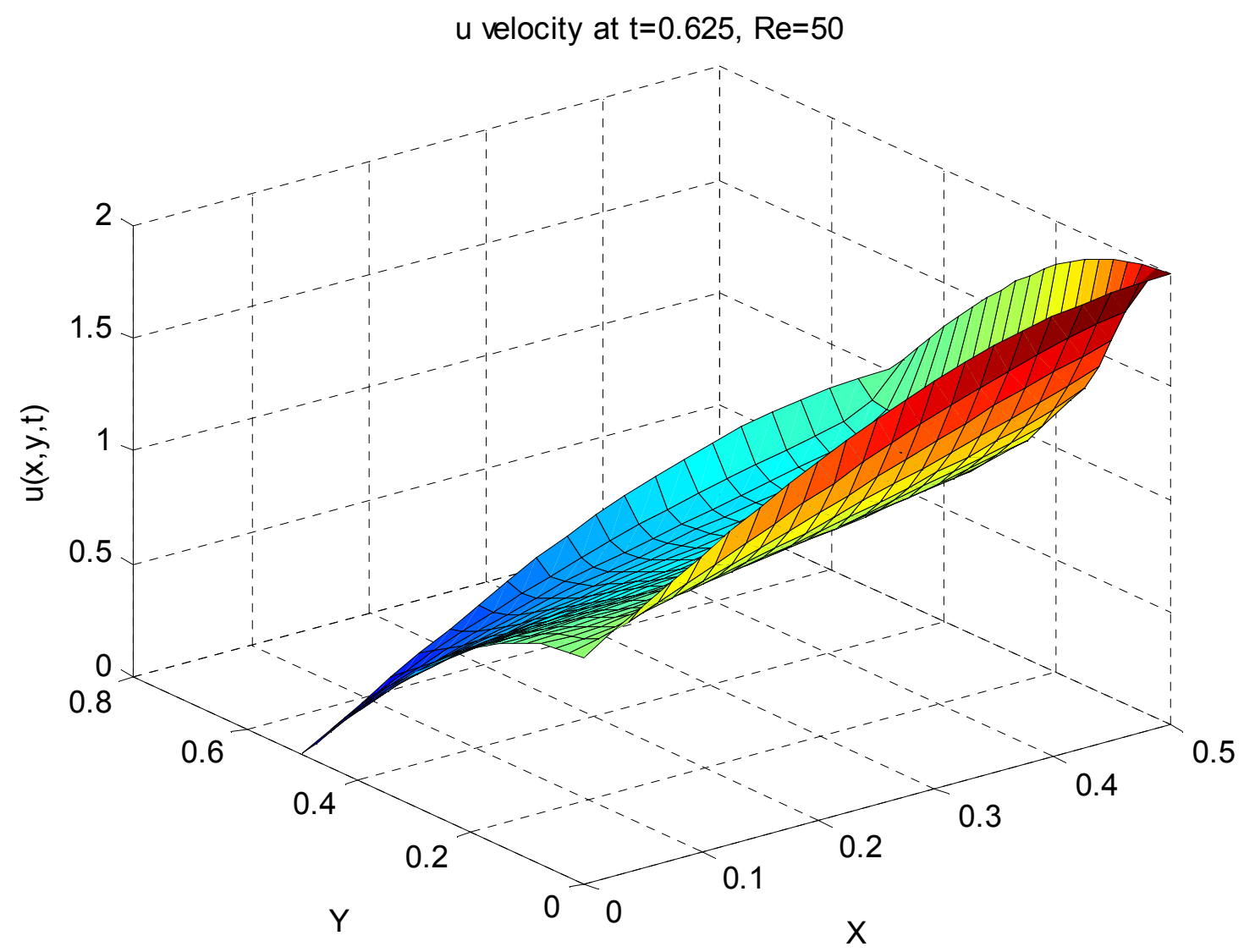

Fig. 2b. $U$ velocity profile at $t=0.625$ for $R e=50, \Delta t=.0001$, (example 2 ).

$u$ velocity at $t=0.625, \operatorname{Re}=100$

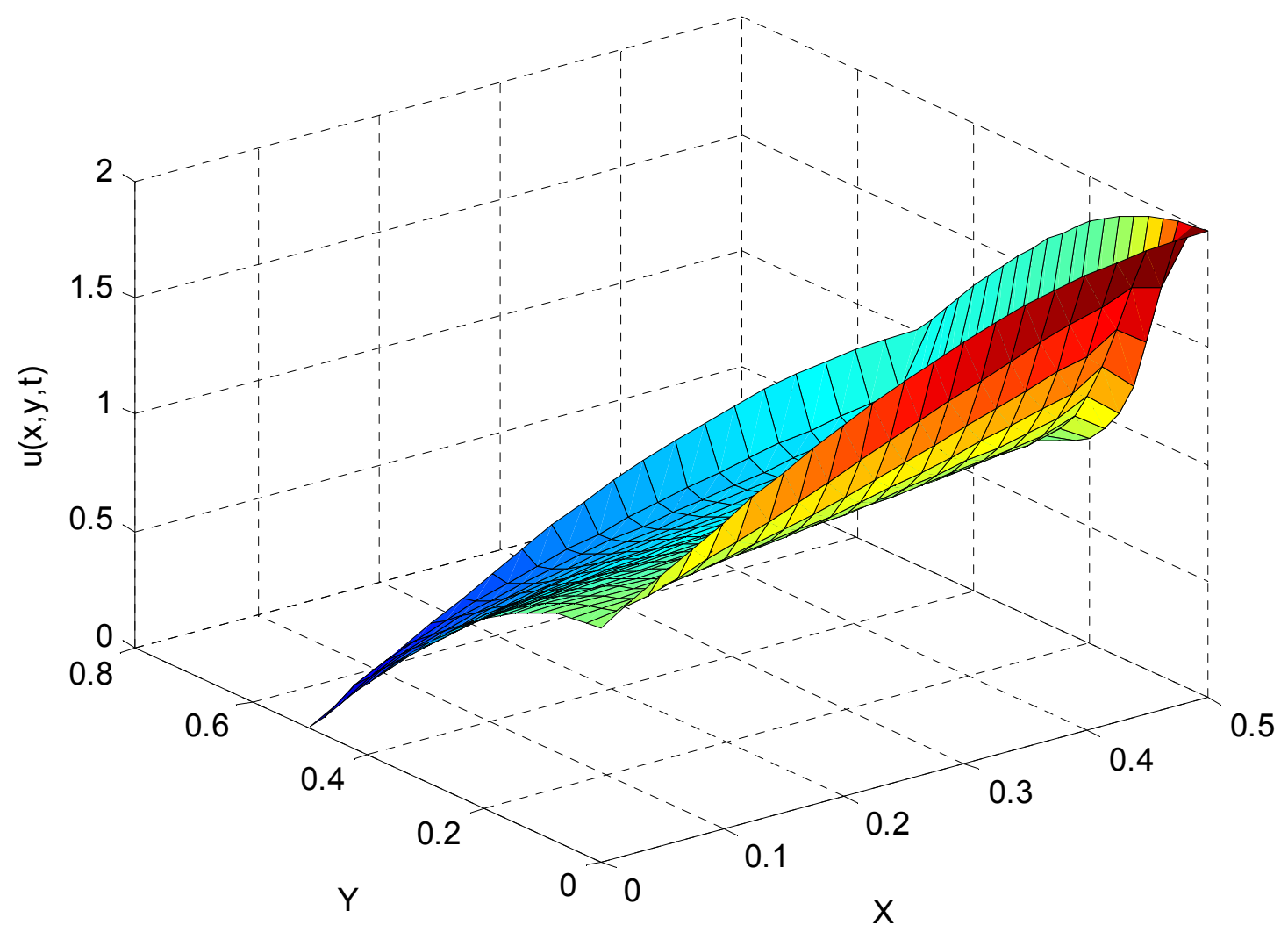

Fig. 2c. U velocity profile at $t=0.625$ for $R e=100, \Delta t=.0001$, (example 2). 


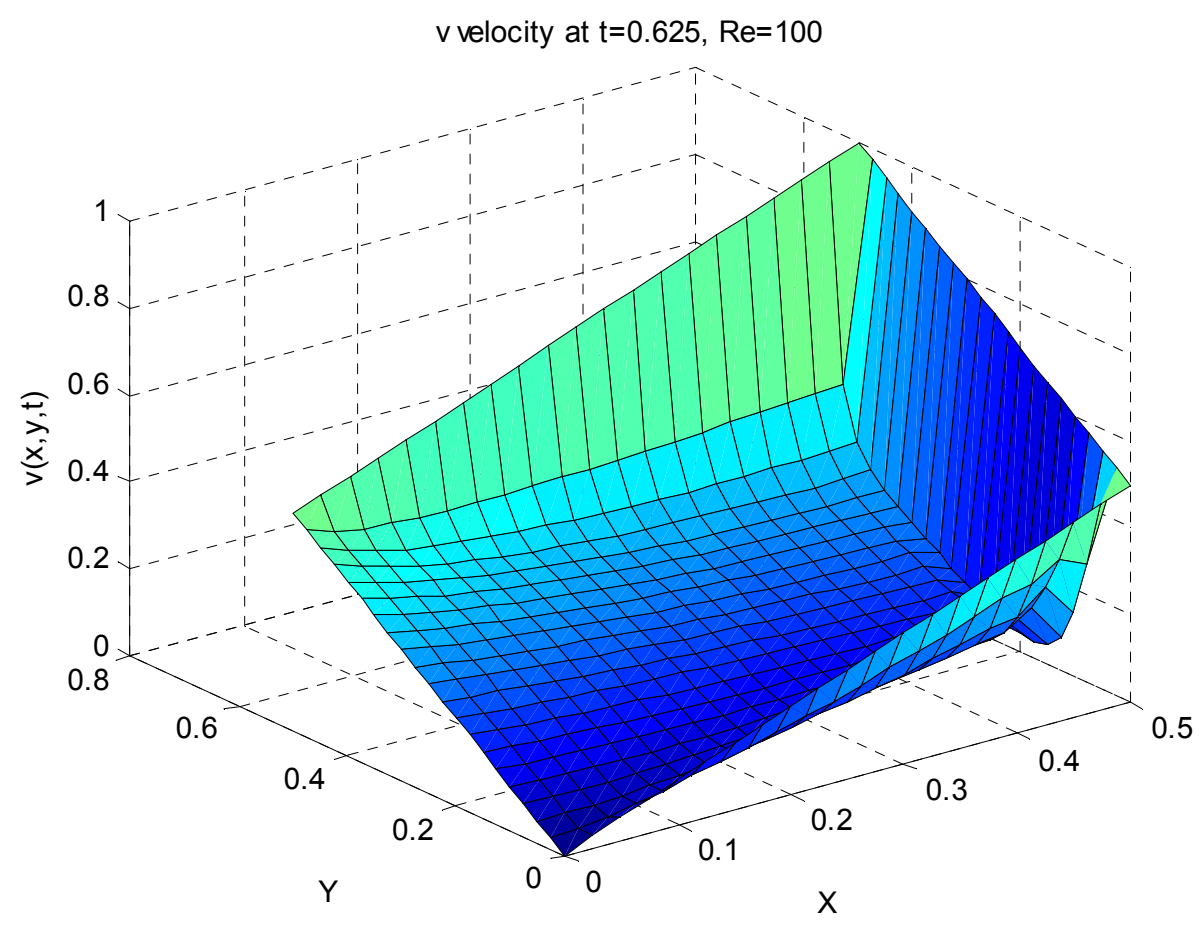

Fig. 2d. V velocity profile at $t=0.625$ for $R e=100, \Delta t=.0001$, (example 2).

\subsection{Problem 3}

The computational domain for the coupled nonlinear Burger's equation is specified as $\Omega=\{(x, y): 0 \leq x \leq 1,0 \leq x \leq 1\}$. It admits the following initial and boundary conditions:

Initial conditions:

$$
\begin{gathered}
u(x, y, 0)=-4 \pi \cos (2 \pi x) \sin (\pi y) / \operatorname{Re}(2+\sin (2 \pi x) \sin (\pi y)), \quad(x, y) \in \Omega \\
v(x, y, 0)=-2 \pi \sin (2 \pi x) \cos (\pi y) / \operatorname{Re}(2+\sin (2 \pi x) \sin (\pi y)), \quad(x, y) \in \Omega
\end{gathered}
$$

Boundary conditions:

$$
\begin{gathered}
u(0, y, t)=-\frac{\left(2 \pi e^{-\left(5 \pi^{2} t / \mathrm{Re}\right)}\right) \sin (\pi y)}{\operatorname{Re}} \quad t \geq 0 \\
u(1, y, t)=-\frac{\left(2 \pi e^{-\left(5 \pi^{2} t / \mathrm{Re}\right)}\right) \sin (\pi y)}{\operatorname{Re}} \quad t \geq 0 \\
u(x, 0, t)=0, \quad t \geq 0, \quad u(x, 1, t)=0, \quad t \geq 0 \\
v(0, y, t)=0, \quad t \geq 0, \quad v(1, y, t)=0, \quad t \geq 0 \\
v(x, 0, t)=-\frac{\left(\pi e^{-\left(5 \pi^{2} t / \mathrm{Re}\right)}\right) \sin (2 \pi x)}{\operatorname{Re}} \quad t \geq 0 \\
v(x, 1, t)=-\frac{\left(\pi e^{-\left(5 \pi^{2} t / \mathrm{Re}\right)}\right) \sin (2 \pi x)}{\operatorname{Re}} \quad t \geq 0
\end{gathered}
$$

The exact solutions are specified as

$$
\begin{gathered}
u(x, y, t)=-\frac{\left(4 \pi e^{-\left(5 \pi^{2} t / \mathrm{Re}\right)}\right) \sin (\pi y) \cos (2 \pi x)}{\operatorname{Re}\left(2+e^{-\left(5 \pi^{2} t / \mathrm{Re}\right)} \sin (2 \pi x) \sin (\pi y)\right)} \\
v(x, y, t)=-\frac{\left(2 \pi e^{-\left(5 \pi^{2} t / \mathrm{Re}\right)}\right) \sin (2 \pi x) \cos (\pi y)}{\operatorname{Re}\left(2+e^{-\left(5 \pi^{2} t / \mathrm{Re}\right)} \sin (2 \pi x) \sin (\pi y)\right)}
\end{gathered}
$$

This example tests the ability of the scheme to handle relatively high Reynolds number. Comparison of numerical and analytical profiles of the velocity profiles (Figs. 3a, 3b, $3 c$ and 3d) and with those of Tamsir and Srivastava [57] confirm accurate results. Tables $3 \mathrm{a}$ and $3 \mathrm{~b}$ give in addition to values relative and average absolute errors confirm the reliability of this formulation. 
Table 3a. Numerical results for u velocity profile at $t=1.0$, for $R e=1000 \Delta t=.0001$ (example 3).

\begin{tabular}{llll}
\hline $\mathbf{( x , \mathbf { y } )}$ & Numerical & Exact & Absolute Error \\
\hline$(0.100000,0.100000)$ & -0.006594 & -0.006498 & 0.000097 \\
$(0.500000,0.100000)$ & 0.007496 & 0.007392 & 0.000103 \\
$(0.900000,0.100000)$ & -0.004835 & -0.005464 & 0.000629 \\
$(0.300000,0.300000)$ & 0.007188 & 0.008171 & 0.000982 \\
$(0.700000,0.300000)$ & 0.004253 & 0.003791 & 0.000462 \\
$(0.100000,0.500000)$ & -0.022465 & -0.024768 & 0.002303 \\
$(0.500000,0.500000)$ & 0.025169 & 0.023923 & 0.001247 \\
$(0.900000,0.500000)$ & -0.013511 & -0.013940 & 0.000429 \\
$(0.300000,0.700000)$ & 0.007188 & 0.008171 & 0.000982 \\
$(0.700000,0.700000)$ & 0.004253 & 0.003791 & 0.000462 \\
$(0.100000,0.900000)$ & -0.006594 & -0.006498 & 0.000097 \\
$(0.500000,0.900000)$ & 0.007496 & 0.007392 & 0.000103 \\
$(0.900000,0.900000)$ & -0.004835 & -0.005464 & 0.000629 \\
\hline
\end{tabular}

relative error $(\mathrm{u})=0.000992$

avg absolute error $(\mathrm{u})=0.000028$

Table 3b. Numerical results for $v$ velocity profile at $t=1.0$, for $R e=1000 \Delta t=.0001$ (example 3).

\begin{tabular}{llll}
\hline $\mathbf{( x ,}, \mathbf{y})$ & Numerical & Exact & Absolute Error \\
\hline$(0.100000,0.100000)$ & -0.007530 & -0.007265 & 0.000265 \\
$(0.500000,0.100000)$ & -0.000648 & -0.000000 & 0.000648 \\
$(0.900000,0.100000)$ & 0.005427 & 0.006109 & 0.000681 \\
$(0.300000,0.300000)$ & -0.009014 & -0.009135 & 0.000121 \\
$(0.700000,0.300000)$ & 0.004326 & 0.004238 & 0.000088 \\
$(0.100000,0.500000)$ & -0.000000 & -0.000000 & 0.000000 \\
$(0.500000,0.500000)$ & -0.000000 & -0.000000 & 0.000000 \\
$(0.900000,0.500000)$ & 0.000000 & 0.000000 & 0.000000 \\
$(0.300000,0.700000)$ & 0.009014 & 0.009135 & 0.000121 \\
$(0.700000,0.700000)$ & -0.004326 & -0.004238 & 0.000088 \\
$(0.100000,0.900000)$ & 0.007530 & 0.007265 & 0.000265 \\
$(0.500000,0.900000)$ & 0.000648 & 0.000000 & 0.000648 \\
$(0.900000,0.900000)$ & -0.005427 & -0.006109 & 0.000681 \\
\hline
\end{tabular}

relative error $(\mathrm{v})=0.000995$

avg absolute error(v) $=0.000007$

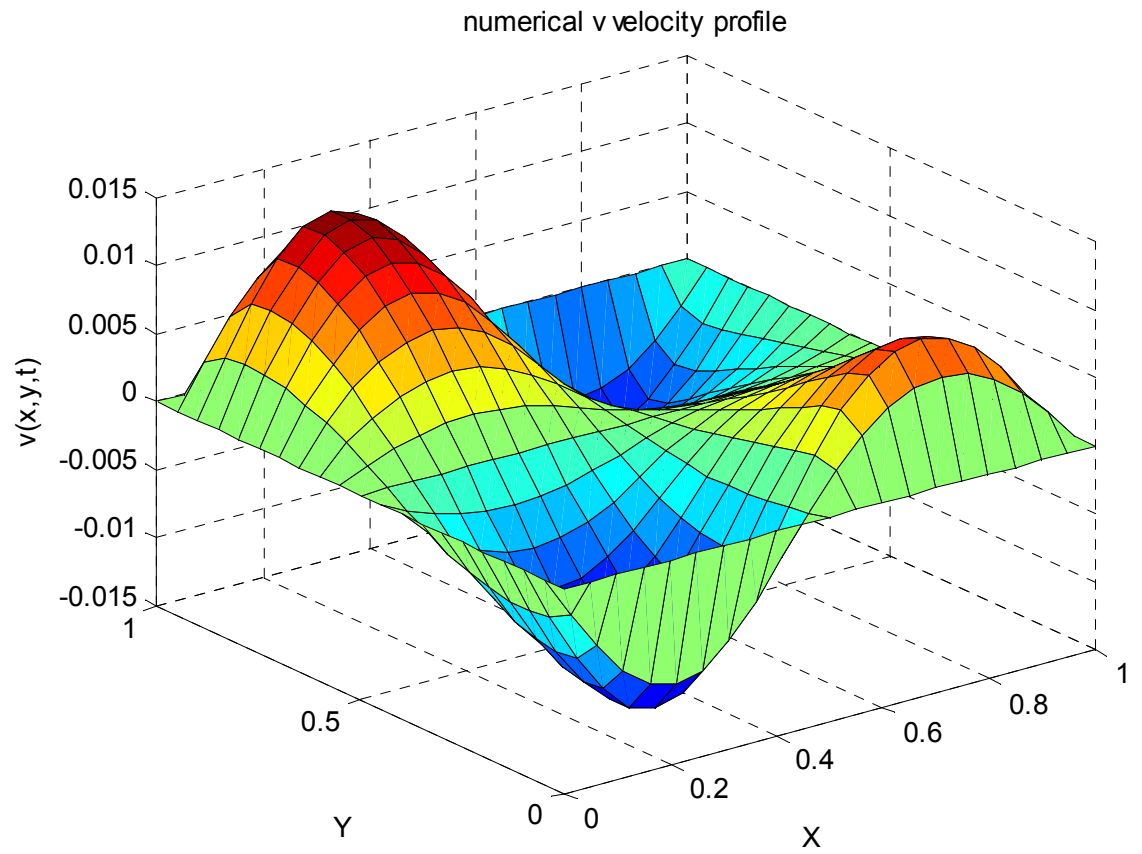

Fig. $3 a$. Numerical $v$ velocity profile at $t=1.0$ for $R e=1000, \Delta t=.0001$, (example 3 ). 


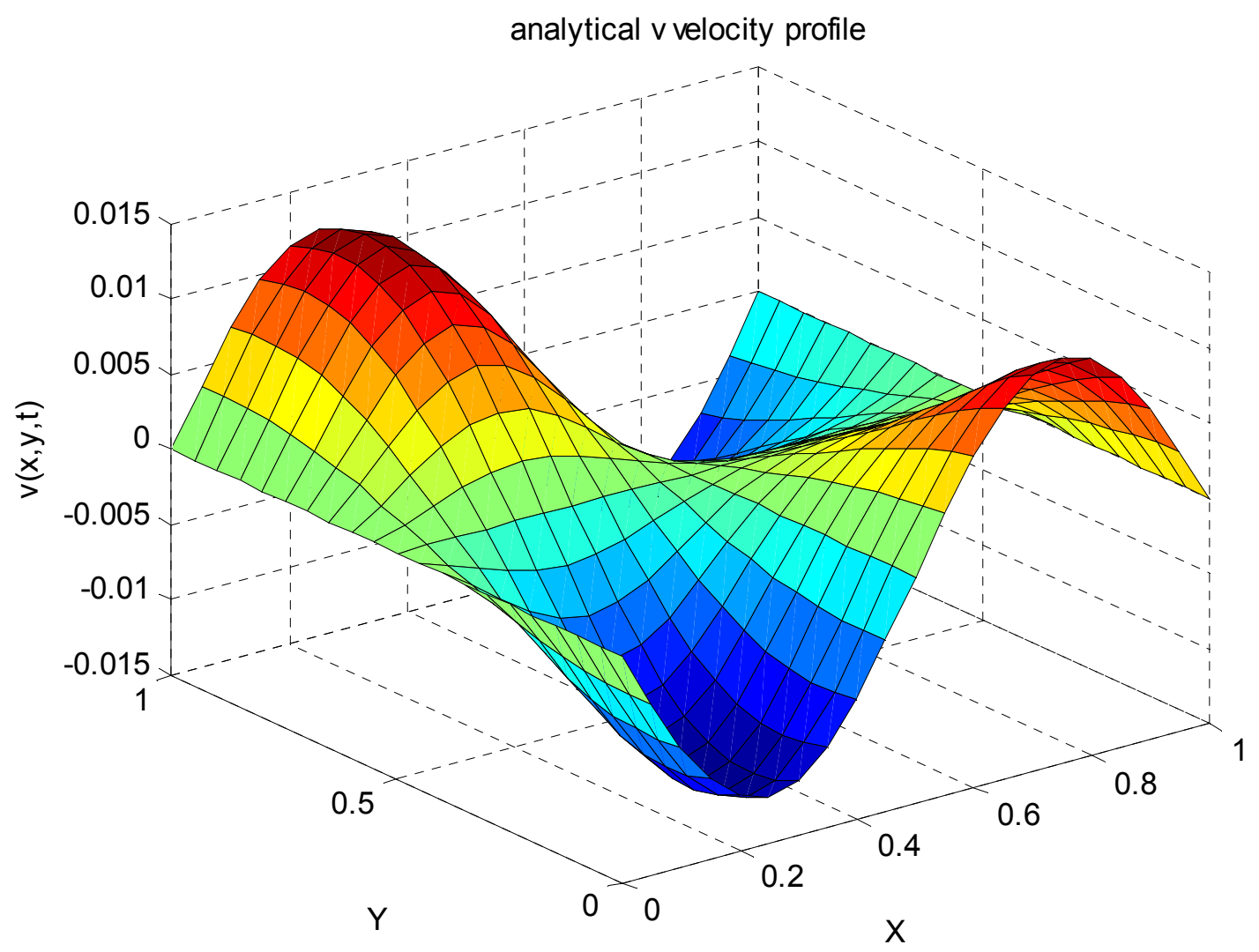

Fig. 3b. Analytical v velocity profile at $t=1.0$ for $R e=1000, \Delta t=.0001$, (example 3 ).

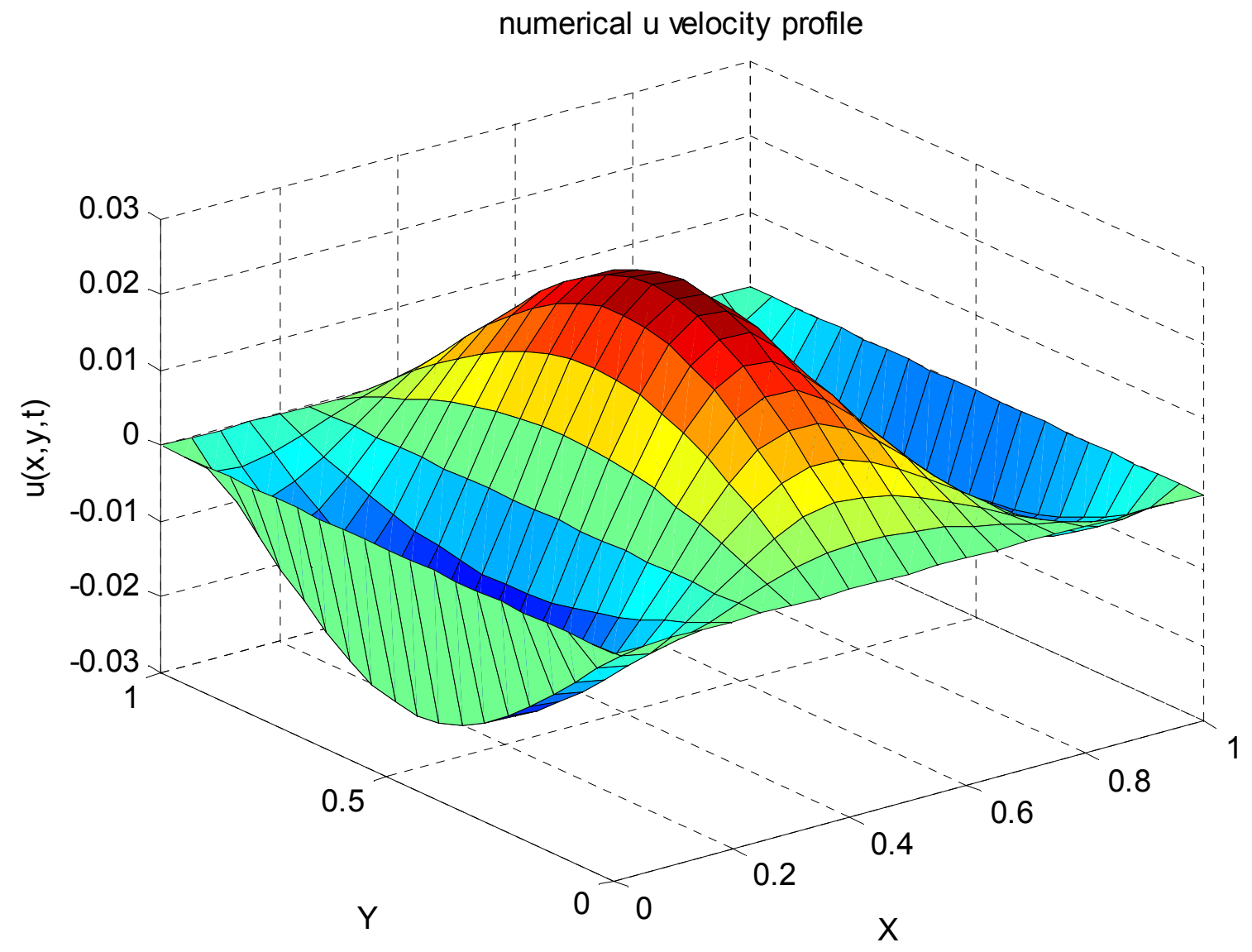

Fig. 3c. Numerical $u$ velocity profile at $t=1.0$ for $R e=1000, \Delta t=.0001$, (example 3). 


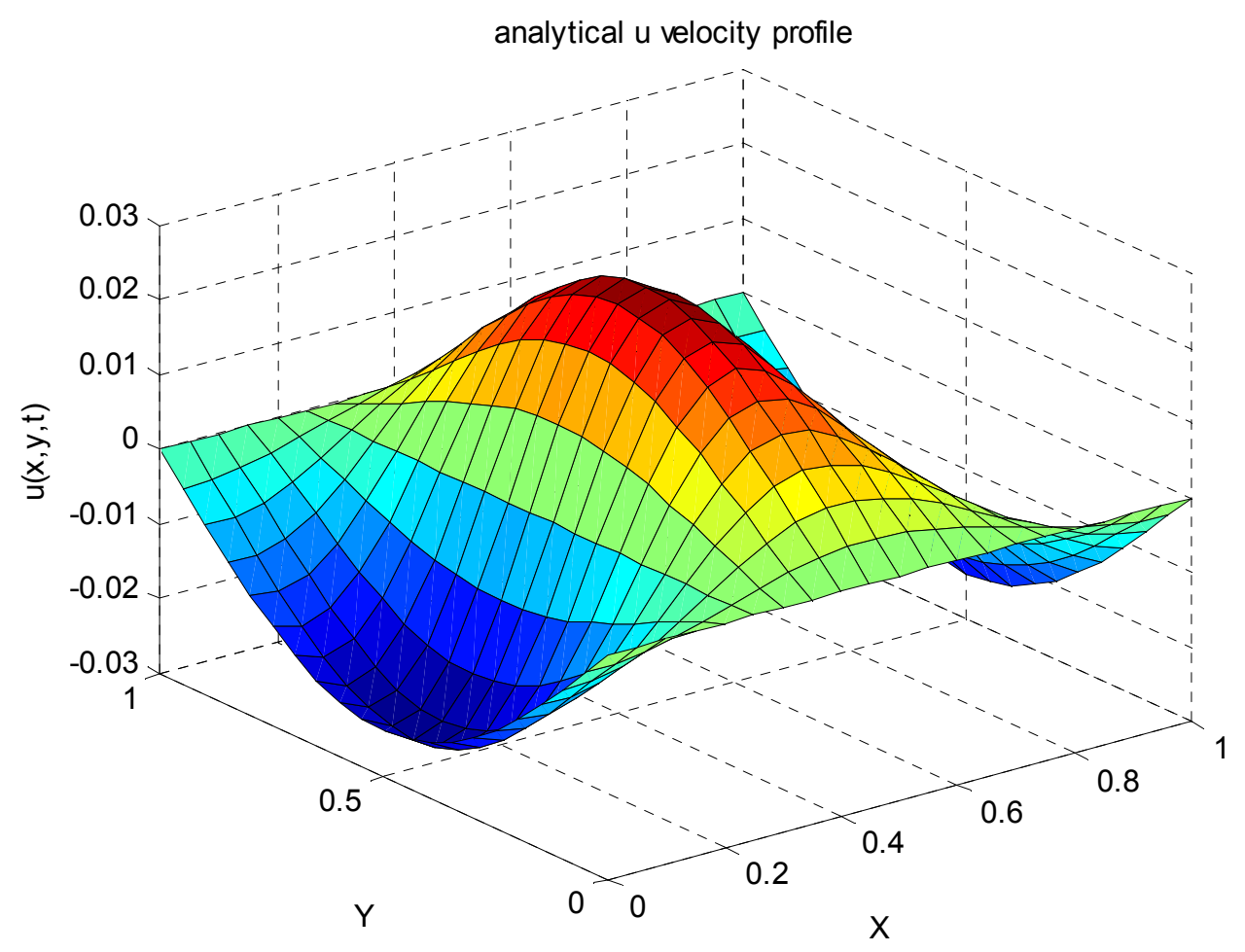

Fig. 3d. Analytical $u$ velocity profile at $t=1.0$ for $R e=1000, \Delta t=.0001$, (example 3)

\section{Conclusion}

By using numerical examples with analytical solutions, we have shown the utility of the recent formulation in handling nonlinear transient coupled nonlinear 2D partial differential equations of the Burger's or Navier-Stokes types [60, 61] in a straightforward manner. The emphasis here is to arrive at a hybrid boundary integral approach devoid of undue complexity in handling some of the major numerical complexities that degrade the competitiveness of the boundary element method. Another equally important consideration is to explore how a relatively straightforward modification of BEM theory could render it accessible to many BEM users when handling the type of problems that relate to real life applications. Accurate representation of the scalar field has been produced in those areas where direct BEM application had previously been deficient.

\section{References}

[1] Cole, J. D., "On the quasilinear parabolic equations occurring in aerodynamics" Quart. Appld. Math. vol. 9 pp. 225-236, 1951.

[2] Nee, J., Duan J., "Limit set of trajectories of the coupled viscous Burger's equations" Appld. Math. Letters vol. 11 (1) pp. 57-61, 1998.

[3] Esipov, S. E., "Coupled Burgers' equations: a model for polydispersive sedimentation" Phs. Rev. vol. 52 p 3711, 1995.

[4] Fletcher, C. A. J., "Generating exact solutions of the twodimensional Burgers' equation” Int. Jnl. Numer. Mthds Fluids vol. 3 pp. 213-216, 1983.

[5] Abazari R., and Borhanifar A., "A numerical study of solution of the Burgers' equations by a differential transformation method", Computers and mathematics with Applications vol. 59 pp. 2711-2722, 2010.

[6] Ablowitz M. J. and Clarkson P. A., Solitons, nonlinear evolution equation and inverse scattering Cambridge: Cambridge University Press, 1991.

[7] Hirota R., "Exact solution of the Korteweg-de Vries equation for multiple collisions of solitons", Phys. Rev. Letters, vol. 27 pp. 1192-1194, 1971.

[8] Bender C. M., Pinsky K. S. and Simmons L. M., "A new perturbative approach to nonlinear problems", Journal of Math. Physics, vol. 30(7) pp. 1447-1455, 1989.

[9] Kaya D., “An explicit solution of coupled viscous Burgers' equations by decomposition method", Int. Jnl. Math. Sci., vol. 27 pp. 675-680, 2001.

[10] Zhu H., Shu H. and Ding M., "Numerical solutions of twodimensional Burgers' equations by discrete Adomian decomposition method" Computers and Mathematics with Applications, vol. 60 (3) pp. 840-848, 2010.

[11] Fletcher, C. A. J., "A comparison of finite element and finite difference solution of the one and two-dimensional Burgers' equations" Jnl. Comput. Physics, vol. 3 pp. 159-188, 1983.

[12] Abdou M. A., Soliman A. A., (2004) " Variational iteration method for solving Burger's and coupled Burger's equations", Jnl. Comput. Appld. Math., vol. 181 (2) pp. 245-251, 2004.

[13] Kelleci A, and Yildrim A., "An efficient numerical method for solving coupled Burgers' equation by combining homotopy perturbation and Pade techniques" Num. Mthds. For Partial Differential Equations, vol. 27 (4), pp. 982-995, 2011. 
[14] Kutluay, S. and Ucar Y., "Numerical solutions of the coupled Burgers' equation by the Galerkin quadratic B-spline finite element method "Mathematical Methods in the Applied Sceinces (wileyonlinelibrary.com), DOI:10.1002/mma.2767, 2013.

[15] Soliman, A. A., "On the solution of two-dimensional coupled burgers' equations by variational iteration method", Chaos Solitons and Fractals, vol. 40 (3), pp. 1146-1155, 2009.

[16] Odibat, Z. M. and Momani S., "Application of variational iteration method to nonlinear differential equations of fractional order", Int. Jnl. Nonlinear Sci. Num. Simulation, vol. 7 pp. $27-34,2006$.

[17] Bahadir, A. R., "A fully implicit finite difference scheme for two-dimensional Burgers' equations”, Appld. Math. and Comput., vol. 137 pp. 131-137, 2003.

[18] Srivastava, V. K. Tamsir, M. and Bhardwaj, Y. and Sanyasiraju, Y., "Crank-Nicolson scheme for numerical solutions of two dimensional coupled Burgers' equations”, Jnl. Scientific and Engnr. Research, vol. 2 (5) pp. 1-7, 2011.

[19] Srivastava, V. K., Singh S. and Awasthi M. K., "Numerical solutions of coupled Burgers' equations by an implicit finite difference scheme", AIP Advances, vol. 3 p. 082131, 2013.

[20] Wubs, F. W. and de Goede, E. D., "An explicit-implicit method for a class of time- dependent partial differential equations", Appld. Numer. Math., vol. 9 pp. 157-181, 1992.

[21] Goyon, O., "Multilevel schemes for solving unsteady equations", Int. Jnl. Num. Mthds. Fluids, vol. 22 pp. 937-959, 1996.

[22] Onyejekwe, O. O., A modified boundary integral solution of coupled linear and nonlinear one dimensional transport equations, Proceed. Boundary elements XXII, eds. Brebbia C. A. and Power H, 2000.

[23] Grigoriev, M. M., "A boundary element method for the solution of convective diffuaion and Burger's equation", Int. Jnl. Num. Mthds Heat and Fluid Flow, vol. 4 (6) pp. 527-552, 1994.

[24] Siraj-ul-Islam, B., Sarler, B. R., Vertnik S., and Kosec G., (2012) "Radial basis function collocation method for the numerical solution of the two-dimensional transient nonlinear coupled Burgers' equations", Appld. Math. Modelling, vol. 36 pp. 1148-1160, 2012.

[25] Toutip, W., The dual reciprocity boundary element method for linear and nonlinear problems $\mathrm{Ph}$. D thesis, University of Hertfordshire, England, 2001.

[26] Percher, R., Harris, S. D., Knipe, R. J. Elliot, L., Ingham, D. B., "New formulation of the Green element method to maintain its second-order accuracy in 2D/FD”, Engnr. Analy. Bdry Elem., vol. 25, pp 211-219, 2001.

[27] Lorinczi, P., Applications of the Green element method to flow in heterogeneous porous media, Ph. D. Thesis University of Leeds, 2006.

[28] Lorinczi. P., Harris S. D. and Elliot, L., (2010) "Unsteady flux-vector-based Green element method", Transport Porous Media, vol. 87 (1) pp 207-228, 2010.

[29] Archer, R., Horne, R. N. and Onyejekwe O. O., Petroleum reservoir engineering applications of the dual reciprocity boundary element method and the Green element method, $21^{\text {st }}$ world conference on the boundary element method, 25-27 August, 1999, Oxford University England, 1999.

[30] Archer, R., Computing flow and pressure transients in heterogeneous media using boundary element methods, $\mathrm{Ph}$. D. dissertation, Stanford University, 2000.

[31] Onyejekwe, O. O., "A comparison of time discretization schemes for the Green element solution of transient heat conduction equation", Num. Heat Transfer, Part B: Fundamentals: An International Journal of Computation and Methodology, vol. 38 (4) pp. 405-422, 2000.

[32] Onyejekwe, O. O., "Experiences in solutions of non-linear transport equations with the Green element method", Int. Jnl. Num. Mthds. Heat and Fluid Flow, vol. 10 (7) 675-686, 2000.

[33] Onyejekwe, O. O. and Onyejekwe, O. N., "Numerical solutions of the one-phase classical Stefan problem using an enthalpy Green element formulation”, Adv. Engnr. Software, vol. 42 (10) pp. 743-749, 2011.

[34] Archer, R. and Horne R. N., (1998) Flow simulations in heterogeneous reservoirs using the dual reciprocity boundary element method and the Green element method, European Conference on the Mathematics of Oil Recovery VI, September 8-11, Peebles, Scotland, 1998.

[35] Taigbenu, A. E., "The Green element method ”, Int. Jnl. Num. Mthds in Engnr., vol. 38 pp. 2241-2263, 1995.

[36] Onyejekwe, O. O., A Green element application to the diffusion equation, Proceedings $35^{\text {th }}$ Heat transfer and Mechanics Institute, California State University, Sacramento California, pp. 75-90 1995.

[37] Onyejekwe, O. O. "Boundary integral procedures for unsaturated flow problems", Transport in Porous Media, vol. 3, pp. 313-330, 1998.

[38] Taigbenu, A. E. and Onyejekwe, O. O., "Green element simulations of the transient nonlinear unsaturated flow equation”, Appld. Math. Mod., vol. 19 pp. 675-684, 1995.

[39] Hibersek, M. and Skerget L, "Domain decomposition methods for fluid flow problems by boundary integral method" Zeitschrift fur Angewandle Mathematik und Mechanic Vol. 76 pp. 115-139, 1996.

[40] Onyejekwe, O. O., "A Boundary element-Finite element equation solutions to flow in heterogeneous porous media" Transport in Porous Media, vol. 31 (3) pp. 293-312, 1998.

[41] Grigoriev, M. M. and Dargush, G. F., "Boundary element methods for transient convective diffusion Part 1: General formulation and 1D implementation" Computer Methods in Appld. Mech. And Engnr., vol. 192 pp. 4281-4298, 2003.

[42] Perata, A. and Popov, V., "Numerical stability of the BEM for advection-diffusion problems" http://dx.doi.org/10.1002/num.2009.

[43] Portapilla, M. and Power H., "iterative solution schemes for quadratic DRM-MD" Num. Mthds. Partial Differential Equations, vol. 24 pp. 1430-1459, 2008.

[44] Sladeck, J., Sladeck V., and Zhang C., "A local BIEM for analysis of transient heat conduction with nonlinear source terms in FMG's" Engnr. Analy. Bdry. Elelm., vol. 28 pp. 1-11, 2004. 
[45] Abashar, M. E., "Application of the Green element method to chemical engineering problems" Journal of King Saud University, vol 17(1) pp. 47-59, 2004.

[46] Mohammadi, M., Hematiyan, M. R., Marin L. "Boundary element analysis of nonlinear transient heat conduction problems involving nonhomogeneous and nonlinear heat sources using time dependent fundamental solutions", Engnr. Analysis Bdry. Elements, vol. 34 pp. 655-665, 2010.

[47] Onyejekwe, O. O., "Green element method for 2D Helmholtz and convection diffusion problems with variable velocity coefficients", Num. Mthds. Partial Diff. Equations, vol. 21 (2) pp. 229-241, 2005.

[48] Onyejekwe, O. O., "A note on Green element method discretization for Poisson equation in polar coordinates", Applied Math Letters, vol. 19 pp 785-788, 2006.

[49] Nyirenda, E., A time dependent Green element Method for potential flow study in 3D Publ. AV Akademi, Kervalag GMBH, 2012.

[50] Bagherinezhad, A. and Pishvaie M. R., "A new approach to counter-current spontaneous imbibition simulation using Green element method", Journ. Petrol. Science and Engnr., vol. 119 pp. 163-168, 2014.

[51] Archer, R. A. and Horne, R. N., (2002) "Green element method and singularity programming for numerical well test analysis", Engnr. Analy. Bdry. Elem, vol. 26 pp 537-546, 2002.

[52] Archer, R. A., "C1 continuous solutions from the Green element method using Overhauser elements", Appld. Numerical Math., vol 56 (2) pp 222-229, 2006.

[53] Onyejekwe, O. O., "An effective boundary integral approach for the solution of nonlinear transient thermal diffusion problems", Italian Jnl. Pure and Appld. Math., vol. 34 pp. $397-$ 412, 2015.

[54] Onyejekwe, O. O., "The effect of time-stepping on the accuracy of the Green element formulation of unsteady convective transport" Jnl. Applied Math and Physics, vol. 2 pp 621-633, 2015

[55] Onyejekwe, O. O., "An Hermitian Boundary integral hybrid formulation for nonlinear Fisher-type equations" Applied and Computaional Mathematics, vol. 4 (3) pp 83-99, 2015.

[56] Onyejekwe, O. O., "Green element procedures accompanied by nonlinear reaction", Int. Jnl. Thermal Sci., vol. 42 pp. 8138202003

[57] Tamsir, M. and Srivastava V. K., "A semi-implicit finitedifference approach for two-dimensional coupled Burgers' equations” Int. Jnl. Of Scientific and Engnr. Res., vol. 2 (6) pp $1-6,2011$.

[58] G $\ddot{u}$ lkac, V., "Numerical solutions of two-dimensional Burgers' equations" International Journal of Scientific and Engineering Research, vol. 6 (4) pp. 215-218, 2015.

[59] Jain, P. C. and Holla, D. N., "Numerical solution of coupled Burgers' equations” Int. Jnl. Num. Mthds. Engngr., vol. 12 pp. 415-428, 1978.

[60] Shukla, H. S., Tamsir, M., Srivastava V. K. and Kumar, J., "Numerical solution of two dimensional coupled viscous Burger equation using modified cubic B-Spline differential quadrature method", AIP advances, vol. 4 p. 117134-1, 2014.

[61] Zhao, G., Yu X., and Zhang R., "The new numerical method for solving the system of two-dimensional Burgers' equations" Computers and Mathematics with Applications, vol. 62 pp. 3279-3291, 2011. 